\title{
Interleukin-17-producing T-helper cells and related cytokines in human airways exposed to endotoxin
}

\author{
P. Glader*, M.E. Smith*, C. Malmhäll ${ }^{\#}$, B. Balder*, M. Sjöstrand", \\ I. Qvarfordt* and A. Lindén*
}

ABSTRACT: Previous studies on mouse models have indicated that interleukin (IL)-17 and IL-17producing T-helper (Th) cells are important for pulmonary host defence against Gram-negative bacteria. Human correlates to these findings have not yet been demonstrated. The aim of the present study was to determine whether or not IL-17-producing Th cells are present and whether IL-17 and other Th17-associated cytokines are involved in the immunological response to endotoxin in human airways.

Segmental exposure to endotoxin and contralateral exposure to vehicle were performed in the lungs of healthy volunteers, with subsequent bronchoalveolar lavage 12 or $24 \mathrm{~h}$ after exposure to study local changes in cytokines and inflammatory cells.

Endotoxin exposure increased concentrations of IL-17, IL-22 and their downstream effector molecules, human $\beta$-defensin-2 and IL-8/CXC chemokine ligand 8 , in bronchoalveolar lavage fluid. Th cells with the capacity to produce IL-17 were found among the bronchoalveolar lavage cells, and expression of IL-17 mRNA correlated with expression of the transcription factor, retinoic-acidreceptor-related orphan receptor $\mathbf{C}$ variant 2 . Moreover, endotoxin increased the numbers of neutrophils, macrophages and IL-17-producing T-cells, as well as the concentration of the Th17regulating cytokines, IL-21 and IL-23.

In conclusion, IL-17-producing Th cells are present, and IL-17, as well as other Th17-associated cytokines, is involved in the immunological response to endotoxin in human airways.

KEYWORDS: Bronchoalveolar lavage, endotoxin, T-helper 17 cells

E vidence from mouse and rat models suggests that the T-cell cytokine interleukin (IL)-17 (also known as IL-17A) is involved in host defence against Gram-negative bacteria in several organs, including the lungs, by linking the activity of certain T-helper cells (Th) to the local accumulation and activity of neutrophils [1-3]. Moreover, the blocking of IL-17 signalling attenuates endotoxin-induced neutrophilia in mouse airways $[4,5]$.

Recent studies on peripheral blood mononuclear cells from mice and humans suggest that a specific subset of Th cells, named Th17, can account for the production of IL-17 in response to components from Gram-negative bacteria [6-9]. These Th17 have been described as $\mathrm{CD}^{+}$ memory T-cells that express IL-23 receptor (IL23R) and, in addition to IL-17, produce IL-22 with or without the Th1 cytokine interferon (IFN)- $\gamma$
$[7,9,10]$. Notably, IL-22 can operate in synergy with IL-17 to induce epithelial production of antibacterial peptides, such as $\beta$-defensins, in response to bacterial infections [11, 12]. Just like IL-17, IL-22 is regulated by IL-23 and is believed to be produced mainly by lymphocytes [7, 11, 13]. Even though the collective evidence for Th17 is intriguing and currently compatible with this particular phenotype being pathogenically important in chronic lung disorders, it remains unclear whether or not Th17 and their cytokines are indeed involved in human pulmonary host defence in vivo [14, 15].

Here, the hypothesis was tested that IL-17producing Th cells are present and that IL-17, as well as other Th17-associated cytokines, is involved in the immunological response to a Gram-negative bacterial stimulus in human airways. This was performed using segmental
AFFILIATIONS

*Lung Immunology Group, Dept of Internal Medicine/Respiratory Medicine and Allergology, and

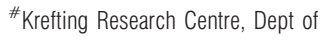
Internal Medicine, Sahlgrenska Academy, University of Gothenburg, Gothenburg, Sweden.

CORRESPONDENCE

P. Glader

Lung Immunology Group Dept of Internal Medicine/Respiratory Medicine and Allergology

Sahlgrenska Academy

University of Gothenburg Box 480

SE 40530

Gothenburg

Sweden

E-mail: pernilla.glader@gu.se

Received:

Oct 282009

Accepted after revision:

Feb 172010

First published online:

Feb 252010 
exposure to endotoxin from Escherichia coli and contralateral exposure to vehicle in healthy volunteers, and thereafter assessing IL-17 and other Th17-associated cytokines and related effector molecules in cell-free bronchoalveolar lavage fluid (BALF) using immunoquantitative PCR (immuno-qPCR) or ELISA. Analysis of T-cell surface antigens and intracellular proteins was also carried out on the BAL cells using flow cytometry. Moreover, the presence of mRNA encoding the critical Th17 transcription factors, retinoic-acid-receptorrelated orphan receptor (ROR) C variant 2 and $R O R \alpha$, as well as IL-17 and IL-22, was verified in the BAL cells.

\section{MATERIALS AND METHODS Study subjects}

The present study was approved by the ethics committee Regional Ethical Review Boad (Gothenburg, Sweden). Written informed consent was obtained from healthy volunteers recruited by advertising. They were all nonsmokers and nonatopic, i.e. gave negative Phadiatop ${ }^{\mathrm{TM}}$ test (Phadia, Uppsala, Sweden) results, without any regular medication. Each subject attended a first visit for medical examination, spirometry and electrocardiography. All of the included subjects showed normal ventilatory lung function, as defined by a forced expiratory volume in $1 \mathrm{~s}$ of $>80 \%$ of the predicted value, and gave normal physical examination and electrocardiography results. Endotoxin exposure took place at visit 2 (bronchoscopy 1) and BAL at visit 3 (bronchoscopy 2). In total, 12 subjects were included in the present study.

\section{Bronchoscopy and BAL sampling}

The clinical protocol for endotoxin exposure and BAL was adapted from O'GRADY et al. [16].

\section{Bronchoscopy 1}

A balloon-tipped catheter was inserted through the bronchoscope, placed in a segmental bronchus and inflated with air to occlude the segments chosen for challenge. A total of $10 \mathrm{~mL}$ $0.9 \%$ PBS, followed by $10 \mathrm{~mL}$ air, was then instilled into the vehicle segment (either right middle lobe or lingula). The bronchoscope was then retracted and moved to the corresponding segment in the contralateral lung. The occlusion procedure was repeated and followed by instillation of $4 \mathrm{ng} \cdot \mathrm{kg}^{-1}$ endotoxin (US Pharmacopeia (USP) reference standard endotoxin from E. coli 0113:H10 (USP, Rockville, MD, USA)) diluted in $10 \mathrm{~mL}$ PBS, followed by $10 \mathrm{~mL}$ air. The bronchoscope was then retracted and the head end of the operating table was elevated $30^{\circ}$ with the subject in place for $1 \mathrm{~h}$ in order to minimise spread of instilled fluid from the challenged segments.

\section{Bronchoscopy 2}

This procedure was performed either 12 or $24 \mathrm{~h}(\mathrm{n}=6$ for both time-points) after the first bronchoscopy, following the same protocol but with a BAL procedure with three 50-mL aliquots of PBS instead of endotoxin instillation. Endobronchial photographs were taken bilaterally on both occasions in order to ensure that BAL sampling was performed in exactly the same segments as had been exposed to endotoxin or vehicle.

\section{Symptom assessment}

Clinical symptoms were recorded by one research nurse during the first $12 \mathrm{~h}$ after the first bronchoscopy procedure using a questionnaire. Both systemic (malaise and headache) and pulmonary (cough, chest pain and mucus) symptoms were assessed, and their severity was quantified by the subjects as none, mild, moderate or severe.

\section{Handling of BAL samples}

BAL samples were centrifuged to separate extracellular fluid from cells, and cell-free BALF was immediately frozen at $-80^{\circ} \mathrm{C}$ until further analysis. Cells were counted and viability estimated through trypan blue exclusion. Cells were then put on cytospin slides or used for flow cytometric analysis. When cell numbers permitted, the remaining BAL cells were kept in RNAlater $^{\mathrm{TM}}$ (Ambion, Austin, TX, USA) at $-80^{\circ} \mathrm{C}$ until analysis of mRNA.

\section{Analysis of soluble BALF cytokines}

The concentration of extracellular IL-17 in cell-free BALF was analysed using immuno-qPCR [17]. The IL-17 immuno-qPCR was developed specifically for the present study in collaboration with a commercial biotechnology company (TATAA Biocenter, Gothenburg, Sweden). This method was chosen instead of regular sandwich ELISA because of its higher sensitivity $\left(0.9 \mathrm{pg} \cdot \mathrm{mL}^{-1}\right)$. The procedure was as follows. Robostrips (AJ Roboscreen, Leipzig, Germany) were coated with capture antibody by overnight incubation with $25 \mu \mathrm{L}$ anti-human IL-17 (eBioscience; $10 \mu \mathrm{g} \cdot \mathrm{mL}^{-1}$ ) at $4^{\circ} \mathrm{C}$. The wells were washed three times with wash buffer before being blocked with incubation buffer for $1 \mathrm{~h}$ at $37^{\circ} \mathrm{C}$. After three washes with wash buffer, $25 \mu \mathrm{L}$ protein sample were added in triplicate and incubated for $1 \mathrm{~h}$ at room temperature. In order to obtain a standard curve, a dilution series of IL-17 (recombinant human IL-17; eBioscience) was added to separate wells in triplicate and incubated in the same way as the samples. The wells were washed six times with wash buffer and incubated with a detection antibody/DNA conjugate (conjugated at TATAA Biocenter; detection antibody from eBioscience), diluted 1:1,000 in incubation buffer, for $1 \mathrm{~h}$ at room temperature. After six washes with wash buffer and 10 with Milli-Q water (produced using UFS elga model Maximal HPLC; Voelia Water, Paris, France), real-time PCR was carried out. Real-time PCR was performed on a Bio-Rad iQ5 real-time PCR instrument (Bio-Rad, Hercules, CA, USA) using FastStart Universal SYBR Green Master (ROX) (Roche, Basle, Switzerland) with a final primer concentration of $0.3 \mu \mathrm{M}$ and total volume of $25 \mu \mathrm{L}$. Cycling conditions were $7 \mathrm{~min}$ at $95^{\circ} \mathrm{C}$ followed by 40 cycles of $10 \mathrm{~s}$ at $95^{\circ} \mathrm{C}, 20 \mathrm{~s}$ at $60^{\circ} \mathrm{C}$ and $20 \mathrm{~s}$ at $72^{\circ} \mathrm{C}$.

All other cytokines, as well as the neutrophil collagenase matrix metalloproteinase (MMP)-8 and human $\beta$-defensin-2, were analysed using sandwich ELISAs: IL-21 (sensitivity $31 \mathrm{pg} \cdot \mathrm{mL}^{-1}$ ), IL-23 (eBioscience, San Diego, CA, USA; sensitivity $15 \mathrm{pg} \cdot \mathrm{mL}^{-1}$ ), IL-22 (sensitivity $7.8 \mathrm{pg} \cdot \mathrm{mL}^{-1}$ ), IL-8/CXC chemokine ligand (CXCL) 8 (sensitivity $3.5 \mathrm{pg} \cdot \mathrm{mL}^{-1}$ ), IL-15 (sensitivity $3.9 \mathrm{pg} \cdot \mathrm{mL}^{-1}$ ), MMP-8 (R\&D Systems, Minneapolis, MN, USA; sensitivity $20 \mathrm{pg} \cdot \mathrm{mL}^{-1}$ ), and human $\beta$-defensin-2 (Phoenix Pharmaceuticals, Burlingame, CA, USA; sensitivity $7.8 \mathrm{pg} \cdot \mathrm{mL}^{-1}$ ). Before analysis of IL-15, IL-17, IL-21, IL-22 and IL-23, the cell-free BALF was concentrated 10-20-fold using Amicon Ultra $5 \mathrm{~K}$ filters (Millipore, Carrigtwohill, Ireland). The figures show protein concentrations that have been 
transformed such that they correspond to unconcentrated BALF.

\section{Flow cytometry}

The BAL cells to be analysed for surface markers were stained with directly conjugated antibodies, fluorescein-isothiocyanateconjugated CD8 (Becton Dickinson, San Diego, CA, USA), phycoerythrin (PE)-conjugated IL-23R (R\&D systems), peridininchlorophyll-protein-conjugated CD3 (Becton Dickinson), allophycocyanin-conjugated CC chemokine receptor (CCR) 6 (R\&D systems), Alexa-Fluor-700-conjugated CD4 (BD Pharmingen, Franklin Lakes, NJ, USA) and matched isotype controls. Cells analysed for expression of intracellular cytokine production were restimulated with phorbol myristate acetate (PMA; SigmaAldrich Sweden, Stockholm, Sweden) and calcium ionophore A23187 (Sigma-Aldrich) in the presence of Golgi stop ${ }^{\circledR}$ (BD Biosciences, San Diego, CA, USA) for $3 \mathrm{~h}$ in vitro. Cells were then harvested and stained with fluorochrome-conjugated antibodies directed against CD3, CD4, CD8 and IL-23R, as indicated above, and with APC-conjugated CD45R0 (BD Pharmingen) or matched isotype antibody controls. Subsequently cells were fixed, permeabilised and stained for IL-17, IFN- $\gamma$ and IL-22. The antibodies used were PE- and Alexa-Fluor-647-conjugated IL-17 (eBioscience; clone eBio64DEC17), PE-conjugated IL-22 (R\&D systems), APC-conjugated IFN- $\gamma$ (BD Pharmingen) and matched isotype antibody controls. Staining for IL-22 was performed after 12 (five subjects) and $24 \mathrm{~h}$ (three subjects) of endotoxin exposure. Double-staining for IL-17 and IFN- $\gamma$ was performed at 12 (three subjects) and $24 \mathrm{~h}$ (four subjects) after endotoxin exposure, and double-staining for IL-17 and IL-23R was performed at 12 (one subject) and $24 \mathrm{~h}$ (five subjects) after endotoxin exposure. All subjects ( $\mathrm{n}=6$ at each time-point) were double-stained for IL-17 and CD45R0. Cells were analysed in a FACSAria (Becton Dickinson).

The number of $\mathrm{CD}^{+} \mathrm{T}$-cells per millilitre of BALF with the capacity to produce IL-17 was calculated as follows: total number of BAL cells per millilitre $\times$ percentage of $\mathrm{CD}^{+}$of total cells $\times$ percentage of $\mathrm{CD}^{+}$of $\mathrm{CD}^{+}$cells $\times$percentage of IL- $17^{+}$of $\mathrm{CD} 4^{+}$cells.

\section{Real-time PCR analysis}

Total RNA purification was performed using an RNeasy Mini Kit (Qiagen, Hilden, Germany) followed by deoxyribonuclease I treatment using a TURBO DNA-free kit (Ambion) in accordance with the manufacturers' protocols. cDNA was prepared using random primers and reagents from Roche using a Gene Amp PCR system 2400 (Perkin Elmer, Wellesley, MA, USA).

The real-time PCR amplification assay was performed on a CFX-96 ${ }^{\mathrm{TM}}$ Real-Time PCR Detection System (Bio-Rad) using sequence-specific primers (TIB MOLBIOL Syntheslabor, Berlin, Germany) and Light Cycler 480 SYBR Green I Master (Roche). Target genes were normalised to the reference gene hypoxanthine guanine phosphoribosyl transferase using CFX Manager $^{\mathrm{TM}}$ Software (Bio-Rad). The primer sequences are shown in table E1 of the online supplementary material.

\section{Statistical analysis}

Differences between sample values from the endotoxinexposed and vehicle-exposed sides of the lung were analysed using the Wilcoxon signed-rank test or Mann-Whitney test, as appropriate. Correlations were calculated using Spearman's rank coefficient. A p-value of $<0.05$ was used as indicator of significance. $\mathrm{n}$ refers to the number of independent observations (equals number of subjects).

\section{RESULTS}

\section{Symptom assessment}

In all but one subject, both systemic and local symptoms were mild during the first $12 \mathrm{~h}$ of observation following endotoxin exposure (table E2 of online supplementary material).

\section{Leukocyte influx}

At $12 \mathrm{~h}$ after endotoxin exposure, there was a substantial increase in the concentration of total cells (17-fold), neutrophils (77-fold), macrophages (6.5-fold) and lymphocytes (10-fold) in BAL samples (fig. 1a and table E3 of online supplementary material). The impact of endotoxin on cell numbers remained present $24 \mathrm{~h}$ after exposure (fig. $1 \mathrm{~b}$ and table E3 of online supplementary material).

\section{Increase in IL-17 and IL-22}

Cell-free BAL fluid samples from the endotoxin-exposed segment displayed an increase in the extracellular concentration of IL-17 compared with the vehicle-exposed segment in all study subjects $12 \mathrm{~h}$ after exposure $(\mathrm{p}=0.031)$ (fig. $2 \mathrm{a})$, and in
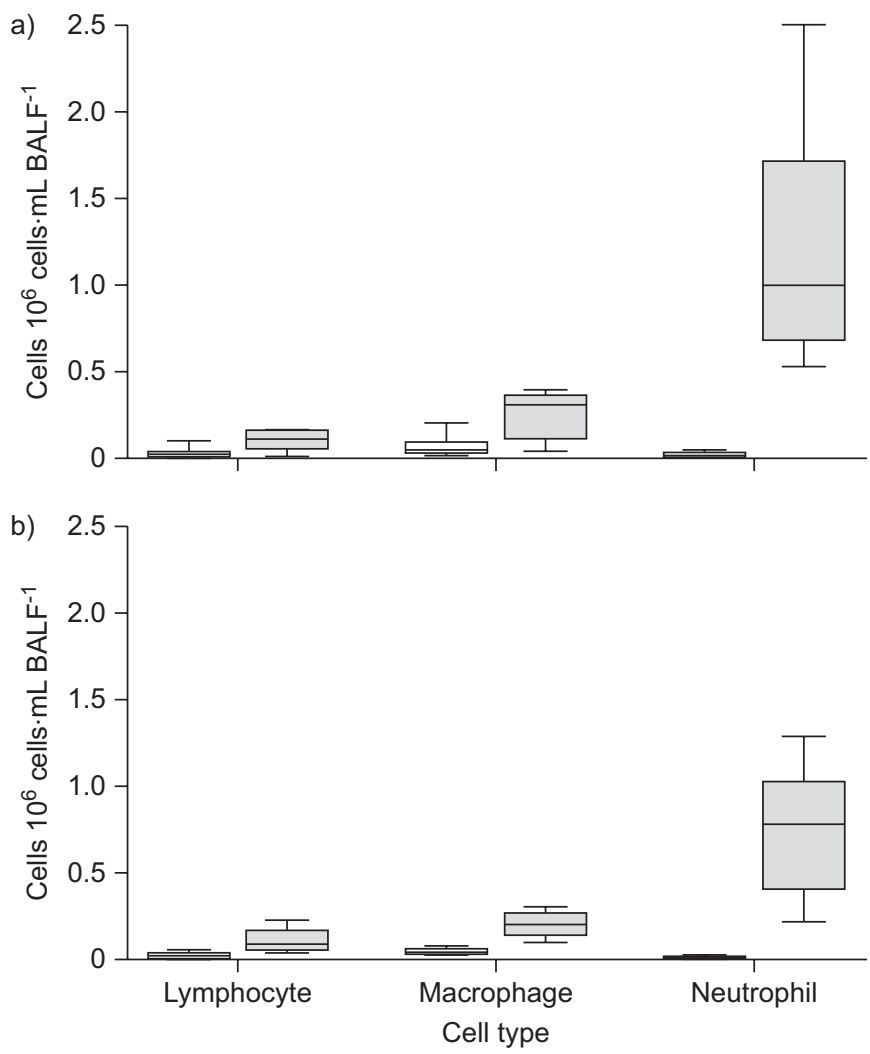

FIGURE 1. Cell concentrations in bronchoalveolar lavage fluid (BALF) samples at: a) $12 \mathrm{~h}$; and b) $24 \mathrm{~h}$. Differential counts of lymphocytes, macrophages and neutrophils from endotoxin-exposed $(\square)$ and vehicle-exposed $(\square)$ segments. Data are from healthy human volunteers ( $\mathrm{n}=6$ for both time-points). Boxes represent median and interquartile range; vertical bars represent ranges. 
five out of six subjects $24 \mathrm{~h}$ after exposure (fig. $2 \mathrm{~b}$ ). There was an analogous increase in the concentration of IL-22 at $12 \mathrm{~h}$ $(\mathrm{p}=0.031)$ (fig. $2 \mathrm{c})$ and $24 \mathrm{~h}$ after endotoxin exposure $(\mathrm{p}=0.031)$ (fig. 2d).

\section{Increase in cytokines upstream of IL-17}

Since the production of both IL-17 and IL-22 is stimulated by IL-23 and Th17 may be influenced by IL-21 and IL-15, these three upstream cytokines were assessed in the BALF samples. Increased concentrations of IL-23 ( $\mathrm{p}=0.031)$ (fig. 3a and $\mathrm{b}$ ) and IL-21 ( $p=0.031)$ (fig. $3 c$ and $d$ ) were found at 12 but not $24 \mathrm{~h}$ after endotoxin exposure. In contrast, the concentrations of IL15 were decreased at $12 \mathrm{~h}$ after endotoxin exposure $(\mathrm{p}=0.031)$ (fig. 3e and f).

\section{Presence of mRNA encoding IL-17, IL-22 and transcription} factors in BAL cells

In order to confirm the presence of mRNA encoding IL-17, IL22 and the transcription factors RORC2 and ROR $\alpha$, mRNA analysis of BAL cells was performed. Owing to the smaller number of cells in BALF from the vehicle-exposed segment of the lung, this mRNA analysis was performed only on BAL cells from the endotoxin-exposed segment. The mRNA analysis revealed the presence of mRNA for IL-17 and IL-22,
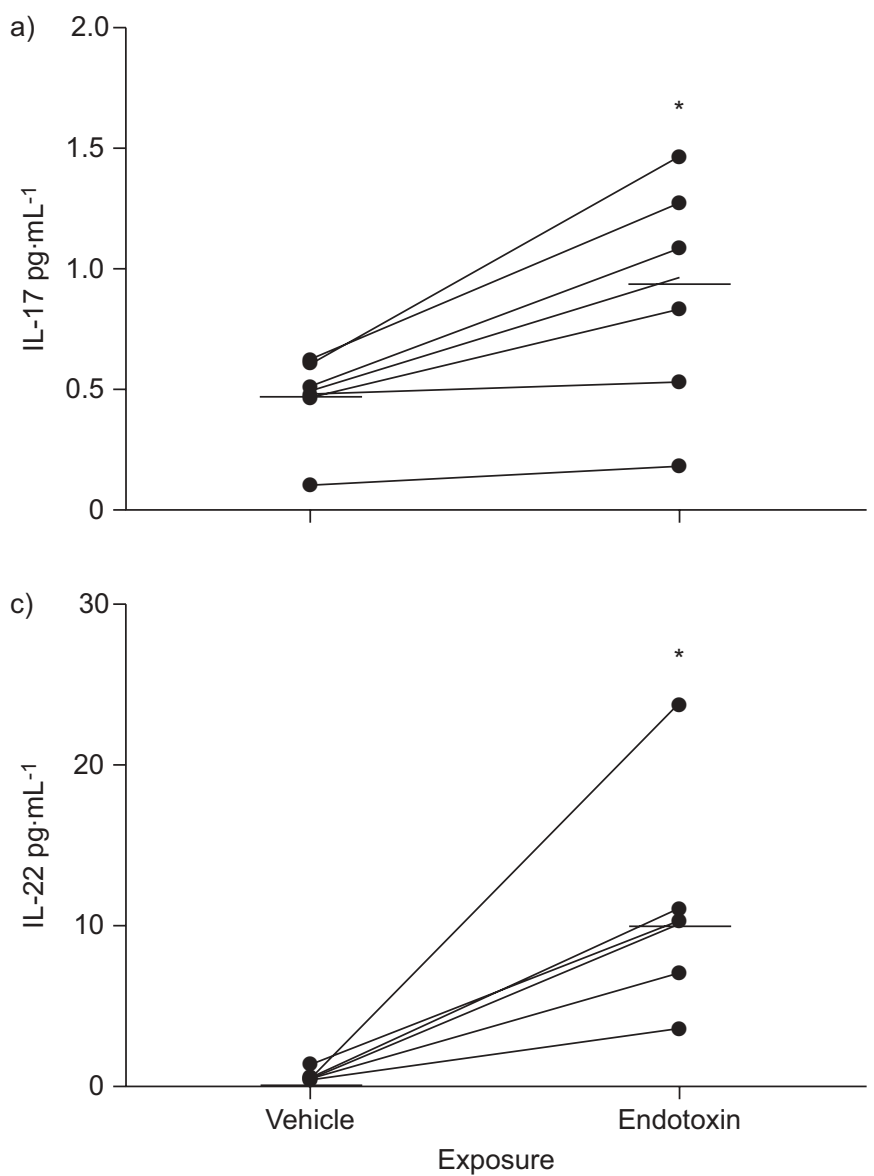

as well as for the transcription factors RORC 2 and $\mathrm{ROR} \alpha$, in all of the subjects analysed. In these BAL cell samples from the endotoxin-exposed segment, the quantity of IL-17 mRNA correlated strongly with the quantity of RORC mRNA (fig. 4a). In contrast, in the same samples, there was no strong or significant correlation between the quantity of IL-17 mRNA and the quantity of $\operatorname{ROR} \alpha$ mRNA (fig. $4 b$ ).

\section{IL-17-producing Th cells in BALF}

In order to identify IL-17-producing cells in the airways, BAL cells were harvested in vivo and flow cytometric analysis performed after $3 \mathrm{~h}$ of subsequent stimulation with PMA and ionomycin in vitro, in the presence of the protein-secretionblocking agent monensin. The intracellular staining with antibodies against IL-17 together with additional antibodies directed against T-cell markers revealed that all IL-17-producing cells were of CD4 origin. At $12 \mathrm{~h}$ after exposure, the percentage of $\mathrm{CD}^{+} \mathrm{CD}^{+}$cells with the capacity to produce IL-17 following in vitro stimulation was 5 (4-11) (median (range)) in BAL samples from the vehicle-exposed segments and 4 (3-12) in BAL samples from the endotoxin-exposed segments. The corresponding percentages for $24 \mathrm{~h}$ after endotoxin exposure were $5(2-8)$ in BAL samples from the vehicle-exposed segments and 5 (3-8) in BAL samples from the endotoxin-exposed segments.

b)

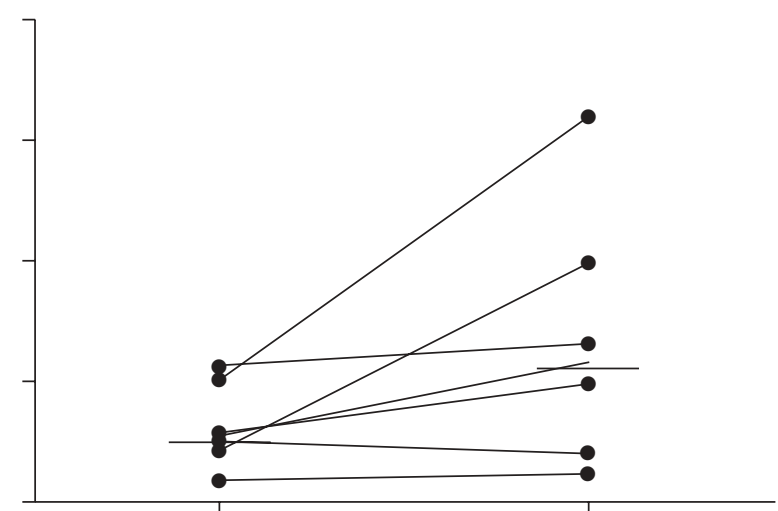

d)

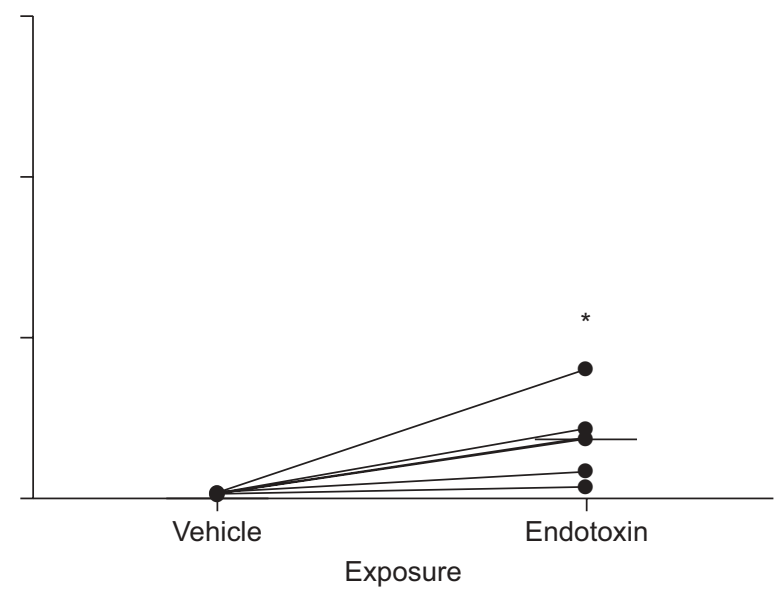

FIGURE 2. a, b) Interleukin (IL)-17 (immunoquantitative PCR); and c, d) IL-22 (ELISA) in cell-free bronchoalveolar lavage fluid from segments exposed to endotoxin $\left(4 \mathrm{ng} \cdot \mathrm{kg}^{-1}\right)$ and vehicle for: a, c) $12 \mathrm{~h}$; and b, d) $24 \mathrm{~h}$. Data are from healthy human volunteers ( $\mathrm{n}=6$ for both time-points). Individual values are shown; horizontal bars represent medians. Extracellular IL-17 and IL-22 levels increase following endotoxin exposure. *: $\mathrm{p}<0.05$ (Wilcoxon signed-rank test) 


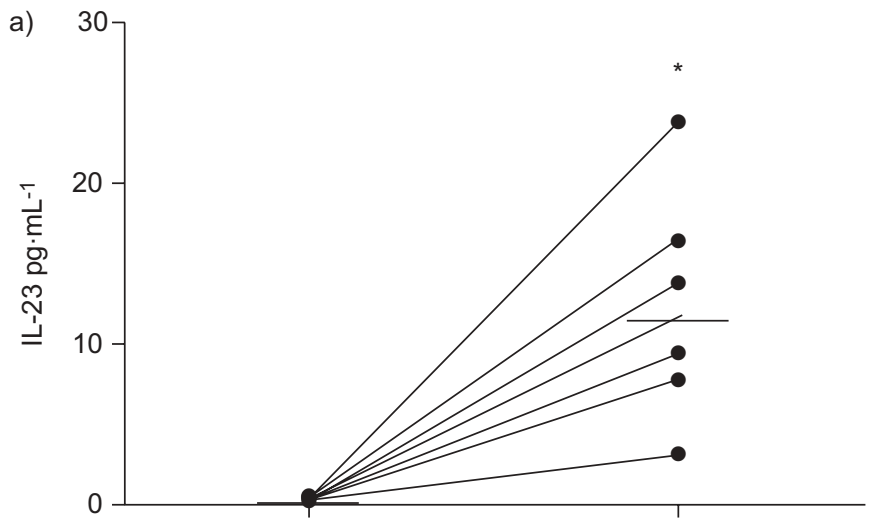

b)

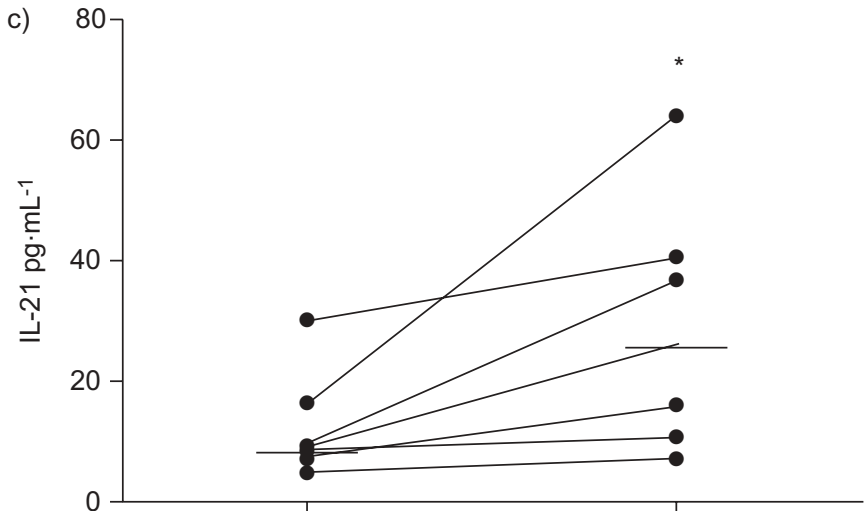

d)

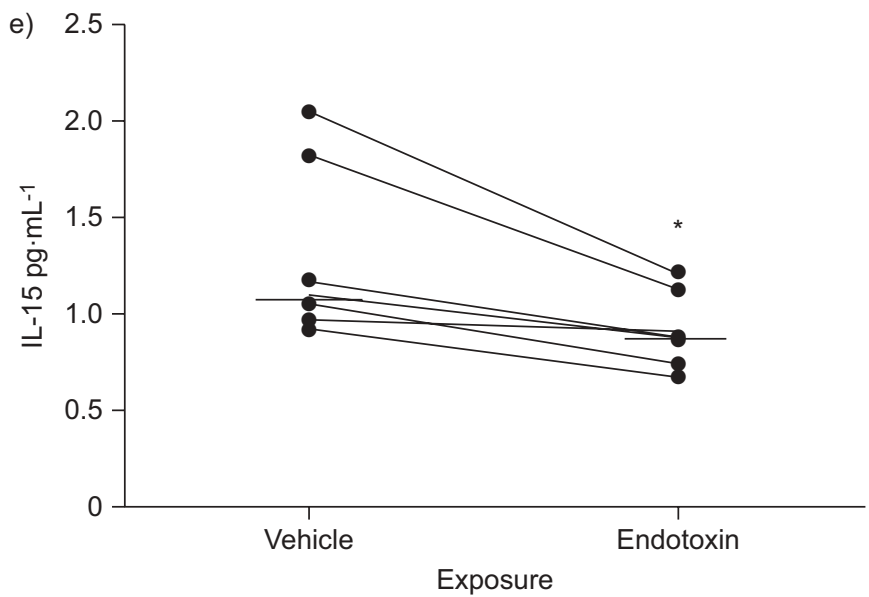

f)

FIGURE 3. a, b) Interleukin (IL)-23; c, d) IL-21; and e, f) IL-15 (ELISA) in cell-free bronchoalveolar lavage fluid from segments exposed to endotoxin and vehicle for: a, c, e) 12 h; and b, d, f) 24 h. Data are from healthy human volunteers ( $n=6$ for both time-points). Individual values are shown; horizontal bars represent medians. Extracellular IL23 and IL-21 but not IL-15 levels increase at $12 \mathrm{~h}$ following endotoxin exposure. *: $\mathrm{p}<0.05$ (Wilcoxon signed-rank test).

Endotoxin exposure increased the number (median (range)) of $\mathrm{CD}^{+}$T-cells with the capacity to produce IL-17 in BAL samples from 347 (154-489) in vehicle-exposed segments to 1,534 (1,045$5,752)$ in endotoxin-exposed segments at $12 \mathrm{~h}$, and from 187 (169-497) in vehicle-exposed segments to $3,212(700-5,502)$ in endotoxin-exposed segments at $24 \mathrm{~h}$. The IL-17 $\mathrm{T}$-cells were all $\mathrm{CD}_{45} \mathrm{RO}^{+}$, indicating memory T-cells (fig. 5). However, unexpectedly, all of the T-cells staining positively for IL-17 lacked IL$23 \mathrm{R}$ expression in BALF from both the endotoxin-exposed and vehicle-exposed segments. Instead, IL-23R was present only on
IL-17-negative cells (fig. 5 and fig. 1E of online supplementary material). Notably, the IL- $17^{+}$cells did not stain positively for IL22 , and the vast majority of the IL-17-producing BAL cells were not producing IFN- $\gamma$ (fig. 5). Even in IL-17-negative T-cells, no reproducible positive intracellular IL-22 signal was found in BAL samples from either the vehicle-exposed segments or the endotoxin-exposed segments at 12 or $24 \mathrm{~h}$ after exposure. The percentage of IL-23R ${ }^{+}$, as well as CD45R0 ${ }^{+}$and CCR6 ${ }^{+}$, T-cells in BAL samples before any in vitro stimulation is shown in table E4 of the online supplementary material. 

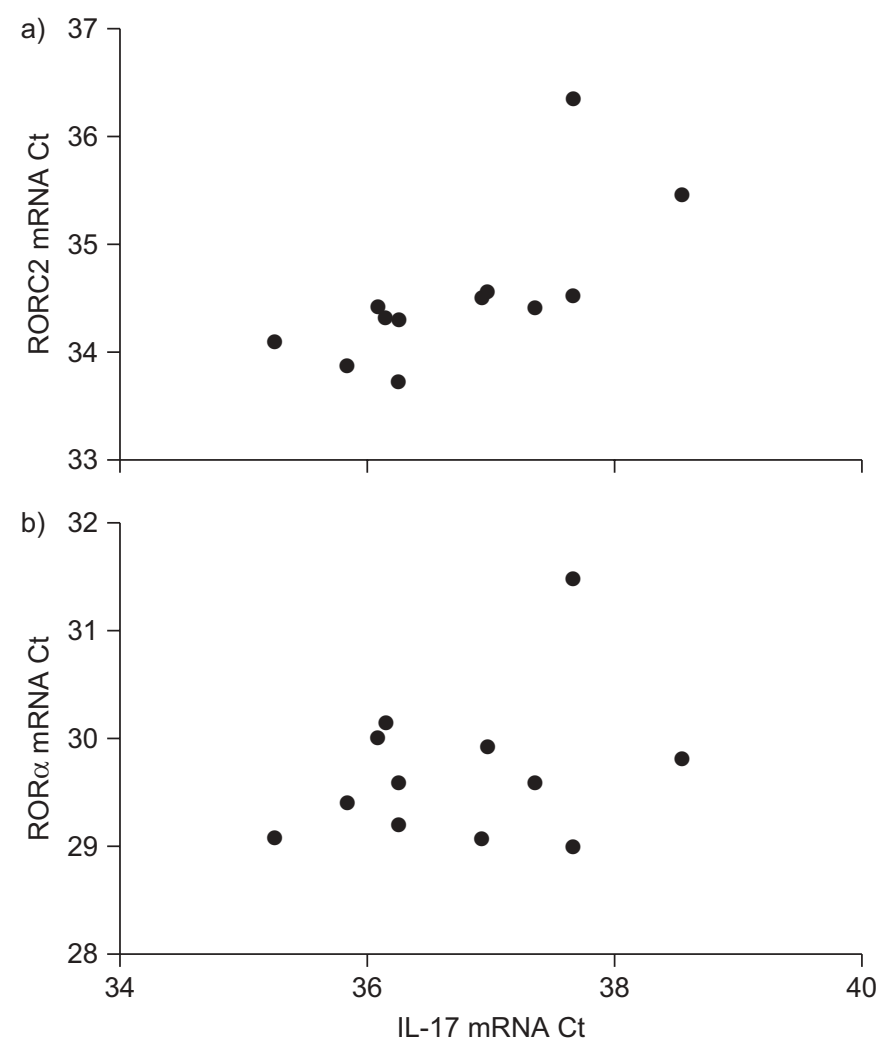

FIGURE 4. Expression of: a) retinoic-acid-receptor-related orphan receptor (ROR) C variant 2; and b) ROR $\alpha$ mRNA (quantitative PCR). Expression of RORC2 but not ROR $\alpha$ mRNA correlates with interleukin (IL)-17 mRNA expression in bronchoalveolar lavage cells from endotoxin-exposed lung segments. Ct: threshold cycle. a) $\rho=0.78 ; p=0.001 ; b) \rho=0.1 ; p=0.37$ (Spearman's rank correlation).

\section{Increase in effector molecules downstream of IL-17 and IL-22}

The extracellular concentrations of the CXC chemokine IL-8/ CXCL8, a well-known downstream effector molecule of IL-17, were clearly elevated in BAL samples from the endotoxinexposed segments at 12 but not $24 \mathrm{~h}$ after exposure (fig. 6a and b). In addition, the extracellular concentrations of MMP-8 were markedly higher in BAL samples from endotoxin-exposed segments at both 12 and $24 \mathrm{~h}$ after exposure (fig. 6c and d). It has been described that IL-17 and IL-22 upregulate the expression of human $\beta$-defensin- 2 in a synergistic manner during infection, and, therefore, the extracellular concentrations of this antimicrobial peptide were also assessed. Concentrations of human $\beta$-defensin- 2 were increased in all cell-free BAL samples from the endotoxin-exposed segments, at both 12 and $24 \mathrm{~h}$ after exposure (fig. 6e and f).

\section{DISCUSSION}

In this study, segmental endotoxin exposure with contralateral exposure to vehicle in the lungs of healthy human volunteers shows that one single exposure to endotoxin results in an accumulation of lymphocytes in the bronchoalveolar space; among these, $\mathrm{CD}^{+} \mathrm{CD} 4^{+} \mathrm{CD} 45 \mathrm{R} 0^{+}$cells with the capacity to produce IL-17. Moreover, endotoxin exposure increased the extracellular protein concentrations of IL-17 and IL-22, as well as IL-21 and IL-23, two upstream regulators of Th17. An endotoxin-induced increase was found in the neutrophilassociated downstream effector molecules IL-8/CXCL8 and the neutrophil collagenase MMP-8, as well as a substantial increase in the number of neutrophils in the BAL samples. In addition, human $\beta$-defensin-2, another key mediator in host defence, was increased in the BAL samples.

This study on healthy volunteers is the first to conclusively demonstrate that there is production of IL-17 in memory Th cells from human BAL samples. This observation, together with the endotoxin-induced increase in the extracellular concentration of IL-17 and number of Th cells, as well as of neutrophils, now shows that IL-17-producing Th cells are indeed involved in the immunological response to endotoxin in human airways. The presence of IL-17 mRNA in the BAL cells provides additional support for the production of IL-17 in these BAL Th cells. In spite of this, the involvement of T-cells positioned outside the bronchoalveolar space, e.g. in the lung tissue, cannot be ruled out in the production and release of the IL-17 that was detected in the current study $[18,19]$. Nor can an additional involvement of cell types other than T-cells be ruled out in the production and release of the IL-17 that was found in the BAL samples [19].

Even though the current findings in humans cannot be predicted from previous studies on mouse models in vivo, they are fully compatible with these studies $[4,5,18,19]$. They are also compatible with previous studies on the impact of organic dust on healthy volunteers [20,21]. Collectively, these studies all indicate the involvement of local IL-17-producing cells during the first 1-2 days of induced neutrophil accumulation in the airways of mammals.

Although IL-17 has already been implicated in inflammatory lung disorders of humans [22-26], and IL-17 and/or IL-17 mRNA has been detected locally in these disorders, the presence of IL-17-containing memory Th cells has not previously been demonstrated in association with increased IL-17 production in the human lungs. The phenotype of the IL17-containing T-cells demonstrated in the present study resembles what has previously been described for Th17 cells $[7,10,27]$ with respect to these cells being $\mathrm{CD} 4^{+}$memory cells. However, the lack of expression of IL-22 and IL-23R on these IL-17-producing Th cells makes it premature to define them as Th17 cells without further characterisation. With this in mind, it is interesting to note that there is previous evidence, fully in line with the current data, on the presence of Th cells that produce IL-17 but not IL-22 in studies on blood cells during mycobacterial infection [28] and on skin in psoriasis and atopic dermatitis [29]. The soluble IL-22 that was found in the cell-free BAL samples may originate from cells other than T-cells, such as lung macrophages, which have been implicated as possible IL-22-producers in a previous study on humans [30].

The fact that IL-23R was not detected on the IL-17-producing Th cells deserves attention. Since IL-23R was detected on CD4 ${ }^{+}$ T-cells, both before and after additional stimulation in vitro, technical artefacts appear to be an unlikely explanation of the present negative findings. Interestingly, very few studies on humans have proven co-localisation of IL-17 and IL-23R on tissue T-cells. One study addressed IL-23R expression on human Th cells from the gut following in vitro stimulation, 

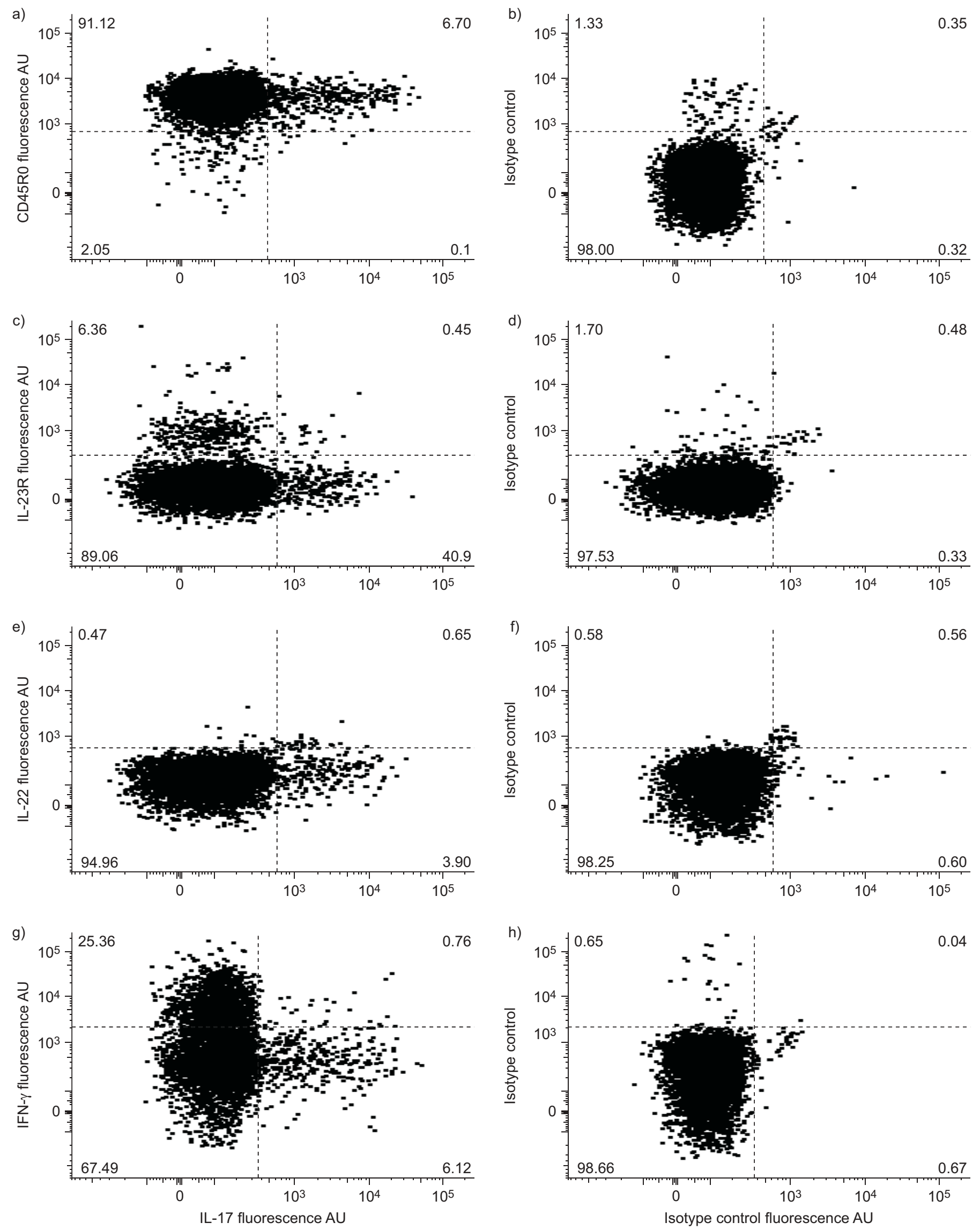
FIGURE 5. Flow cytometric dot plots gated on $\mathrm{CD}^{+} \mathrm{CD}^{+}$bronchoalveolar lavage (BAL) cells in a representative subject showing staining of cells with: a) $\mathrm{CD} 45 \mathrm{RO}$; c) interleukin (IL)-23 receptor (IL-23R); e) IL-22; and g) interferon (IFN)- $\gamma$ together with IL-17; and with: b, d, f, h) their respective isotype controls. Before flow cytometric analysis, the BAL cells were stimulated in vitro for $3 \mathrm{~h}$ in the presence of phorbol myristate acetate, ionomycin and monensin. The figures in the four corners of the plot represent the percentage of dots falling in each quarter of the plot. $\mathrm{CD} 3^{+} \mathrm{CD} 4^{+} \mathrm{IL}-17^{+} \mathrm{BAL}$ cells express $\mathrm{CD} 45 \mathrm{R} 0$ but not IL-23R, IFN- $\gamma$ or IL-22. AU: arbitrary unit.

using anti-CD3 and anti-CD28. In that study, it was claimed that the IL-17-producing cells expressed IL-23R mRNA, but no corresponding data on IL-23R protein were shown [31]. Moreover, a study on peripheral blood mononuclear cells from patients with rheumatoid arthritis and ankylosing spondylitis showed that $\sim 50 \%$ of the IL-17-containing Th cells express IL-23R protein, whereas the rest do not [32]. Compatible with the current findings, a study on human blood cells differentiated in vivo indicates that both IL-23R ${ }^{+}$
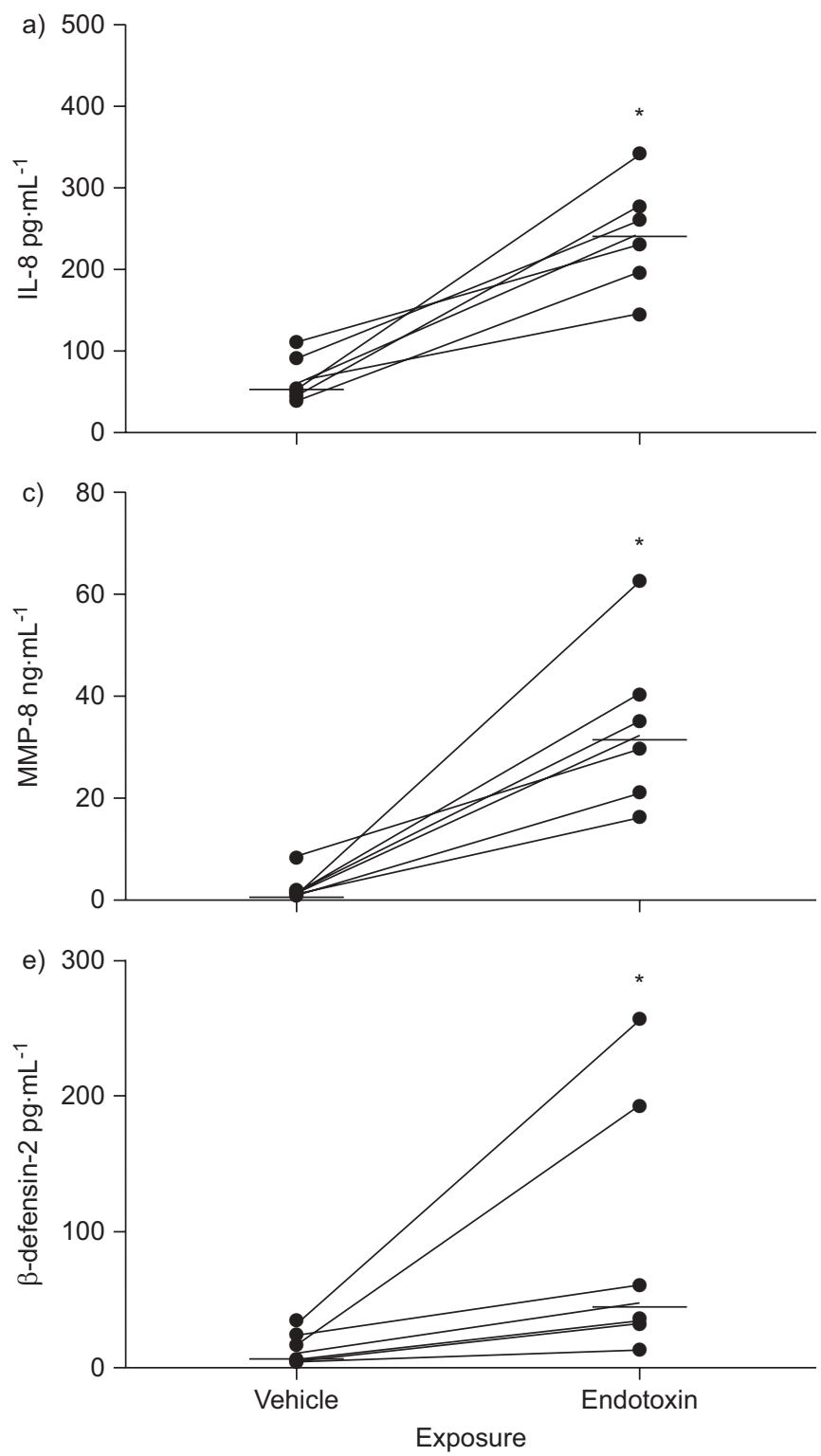

and IL-23R $\mathrm{R}^{-}$fractions of Th cells can produce IL-17 when restimulated in vitro [27]. On the one hand, this suggests that IL-23R does not have to be present at the specific time-point at which Th cells produce IL-17. On the other hand, IL-23 is believed to be an important cytokine in the stabilisation of the Th17 phenotype $[33,34]$. Moreover, a recent study on IL-23R knockout and chimera mice suggests that IL-23 is involved in the late phase of differentiation, rather than being required for effector functions of Th17 cells [35]. In view of these findings, it

b)

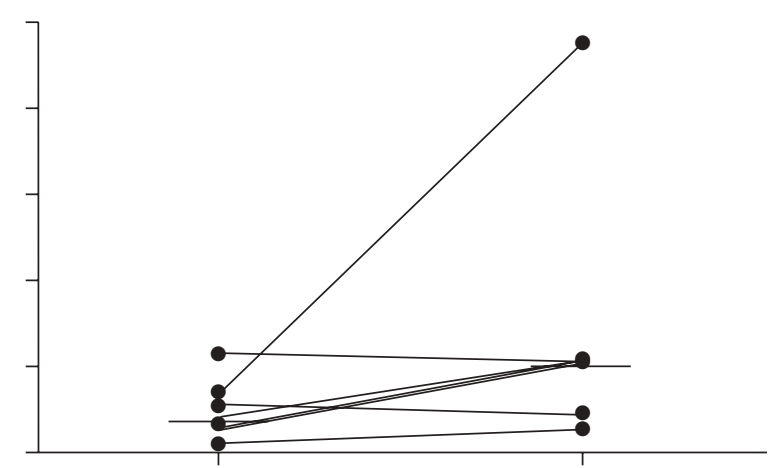

d)

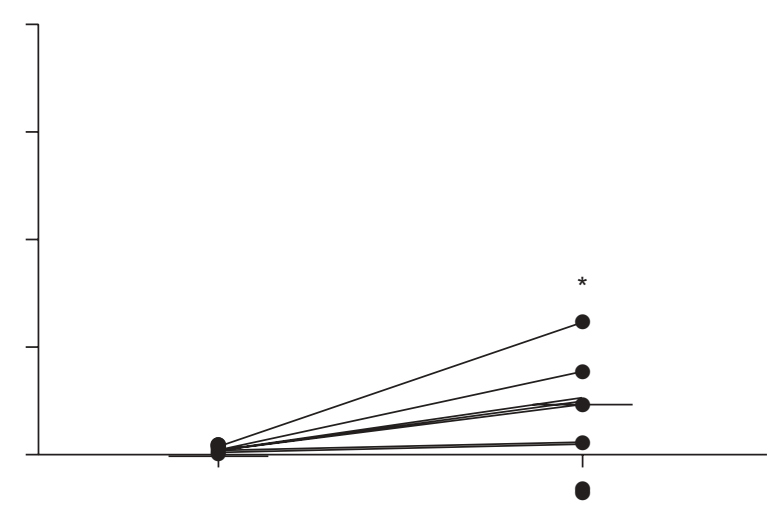

f)

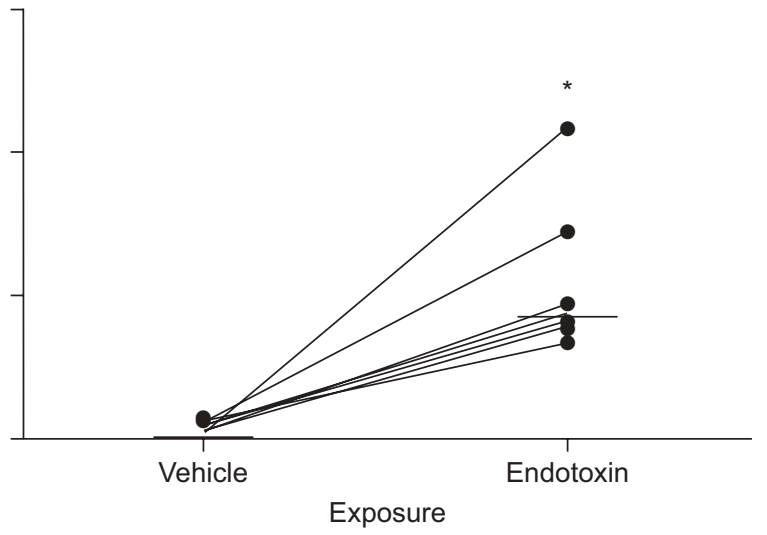

FIGURE 6. a, b) Interleukin (IL)-8 (or CXC chemokine ligand 8); c, d) matrix metalloproteinase (MMP)-8; and e, f) human $\beta$-defensin-2 (ELISA) in cell-free bronchoalveolar lavage fluid from segments exposed to endotoxin and vehicle for: a, c, e) 12 h; and b, d, f) 24 h. Data are from healthy human volunteers ( $n=6$ for both time-points). Individual values are shown; horizontal bars represent medians. Levels of downstream extracellular effector cytokines of IL-17 are increased following endotoxin exposure. *: $p<0.05$ (Wilcoxon signed-rank test). 
is possible that the IL-17-producing Th cells in human airways are fully differentiated effector cells no longer in need of expressing IL-23R on their surface in order to be able to produce and release IL-17.

IL-21, one of the Th17-associated cytokines that was assessed in the present study, is believed to be of importance for the stabilisation of the Th17 phenotype and for the expression of the transcription factor RORC2 [34, 36, 37]. In the present study it was found that, as for IL-23, segmental endotoxin exposure increased extracellular concentrations of IL-21 in cell-free BAL samples $12 \mathrm{~h}$ after this exposure. Notably, the increase in IL-21 and IL-23 was transient; the concentrations of both of these cytokines had more or less returned to their baseline levels after $24 \mathrm{~h}$. This time course pattern suggests a rapid response for the initiation of IL-17 and IL-22 production, a production that was still ongoing $24 \mathrm{~h}$ after endotoxin exposure. Moreover, when quantifying mRNA encoding the transcription factor RORC2 and IL-17, respectively, a strong correlation was found between these two end-points, an observation which is compatible with a critical role for RORC2 in the transcription of IL-17 in human lungs. Interestingly, no such correlation was found for mRNA encoding ROR $\alpha$ and IL-17, which is compatible with ROR $\alpha$ being of lesser importance for IL-17 transcription in human lungs, at least in response to endotoxin.

In contrast to IL-21, endotoxin exposure did not increase levels of IL-15, a cytokine believed to be involved in both innate and acquired immunity $[38,39]$. The rationale for measuring IL-15 was that previous studies suggest that this cytokine can function as a trigger of IL-17 secretion in human peripheral blood mononuclear cells cultured in vitro [40]. In addition, IL15 mRNA has been found in mice BAL cells following exposure to endotoxin [4]. However, the results of the current study indeed revealed somewhat lower concentrations of IL-15 in cell-free BALF from endotoxin-exposed segments. It can be speculated that the explanation for this finding is related to IL15 regulating the balance between T-regulatory cell and Th17 populations [41].

Both IL-17 and IL-22 have been shown to play important roles in inducing antibacterial activity in epithelial cells, through the production of antimicrobial proteins. The potentially critical importance of this defence mechanism during bacterial infection caused by Gram-negative species was recently demonstrated in a study on mice infected by Klebsiella pneumoniae [42]. In the present study, the concentration of the antimicrobial peptide human $\beta$-defensin- 2 was substantially increased following endotoxin exposure. Thus the presence of human $\beta$-defensin-2 in the human lung may serve at least two purposes: to function as an antimicrobial peptide; and to act as a chemoattractant for T-cells expressing the chemokine receptor CCR6, which was present on a subpopulation of BAL Th cells from both endotoxin- and vehicle-exposed lung segments in the present study.

In the BAL samples from endotoxin-exposed segments, the extracellular concentrations of the potent chemokine IL-8/ CXCL8, as well as the numbers of neutrophils, were substantially higher than in the corresponding samples from vehicleexposed segments. In addition, the extracellular concentration of the neutrophil collagenase MMP-8 was markedly increased in BAL samples from endotoxin-exposed segments. Even if the cause effect-relationship for IL-17 cannot be proven in this respect, the present observations are fully compatible with IL-17 contributing to the accumulation of active neutrophils in human airways, given the increase in IL-17 that was also demonstrated. Future studies are warranted to generate definitive evidence for this in human lungs.

In spite of the clear statistical significance demonstrated for all of the present key findings, it could be argued that the observed concentrations of IL-17 were relatively low and that the endotoxin-induced increase in IL-17 concentration was modest. However, given the fact that the BAL procedure per se introduces a tremendous dilution of certain microcompartments in the airways, including the bronchial epithelial lining fluid compartment, this argument does not diminish the potential biological significance of the current findings.

In conclusion, IL-17-producing memory Th cells are present, and IL-17, as well as other Th17-associated cytokines, such as IL-21 and IL-22, is involved in the immunological response to endotoxin in human airways. We believe that the most important aspect of the current findings is that we have now proven that there is a human in vivo correlate to the IL-17producing cells that have previously been demonstrated in several studies on mouse lungs following bacterial stimulation. The current findings thereby provide a rationale for a more indepth characterisation of IL-17-producing memory Th cells in human lung disease.

\section{SUPPORT STATEMENT}

This study was supported by the Swedish Heart-Lung Foundation (Stockholm, Sweden; Project No. 20070471), the Swedish Research Council (Stockholm, Sweden; Project No. K2008-57X-09048-19-3) and Swedish federal government (Stockholm, Sweden) funding according to the ALF/LUA agreement.

\section{STATEMENT OF INTEREST}

None declared.

\section{REFERENCES}

1 Laan M, Cui Z-H, Hoshino $\mathrm{H}$, et al. Neutrophil recruitment by human IL-17 via C-X-C chemokine release in the airways. J Immunol 1999; 162: 2347-2352.

2 Hoshino H, Lötvall J, Skoogh BE, et al. Neutrophil recruitment by interleukin-17 into rat airways in vivo. Role of tachykinins. Am Respir Crit Care Med 1999; 159: 1423-1428.

3 Hoshino H, Laan M, Sjöstrand M, et al. Increased elastase and myeloperoxidase activity associated with neutrophil recruitment by IL-17 in airways in vivo. J Allergy Clin Immunol 2000; 105: 143-149.

4 Ferretti S, Bonneau O, Dubois GR, et al. IL-17, produced by lymphocytes and neutrophils, is necessary for lipopolysaccharideinduced airway neutrophilia: IL-15 as a possible trigger. J Immunol 2003; 170: 2106-2112.

5 Miyamoto M, Prause O, Sjöstrand M, et al. Endogenous IL-17 as a mediator of neutrophil recruitment caused by endotoxin exposure in mouse airways. J Immunol 2003; 170: 4665-4672.

6 Happel KI, Zheng M, Young E, et al. Cutting edge: roles of Tolllike receptor 4 and IL-23 in IL-17 expression in response to Klebsiella pneumoniae infection. J Immunol 2003; 170: 4432-4436. 
7 Acosta-Rodriguez EV, Napolitani G, Lanzavecchia A, et al. Interleukins $1 \beta$ and 6 but not transforming growth factor- $\beta$ are essential for the differentiation of interleukin 17-producing human T helper cells. Nat Immunol 2007; 8: 942-949.

8 Kolls JK, Lindén A. Interleukin-17 family members and inflammation. Immunity 2004; 21: 467-476.

9 Korn T, Bettelli E, Oukka M, et al. IL-17 and Th17 cells. Annu Rev Immunol 2009; 27: 485-517.

10 Wilson NJ, Boniface K, Chan JR, et al. Development, cytokine profile and function of human interleukin 17-producing helper $\mathrm{T}$ cells. Nat Immunol 2007; 8: 950-957.

11 Liang SC, Tan XY, Luxenberg DP, et al. Interleukin (IL)-22 and IL-17 are coexpressed by Th17 cells and cooperatively enhance expression of antimicrobial peptides. J Exp Med 2006; 203: 2271-2279.

12 Wolk K, Witte E, Wallace E, et al. IL-22 regulates the expression of genes responsible for antimicrobial defense, cellular differentiation, and mobility in keratinocytes: a potential role in psoriasis. Eur J Immunol 2006; 36: 1309-1323.

13 Zheng Y, Danilenko DM, Valdez $\mathrm{P}$, et al. Interleukin-22, a $\mathrm{T}_{\mathrm{H}} 17$ cytokine, mediates IL-23-induced dermal inflammation and acanthosis. Nature 2007; 445: 648-651.

14 Ivanov S, Lindén A. Interleukin-17 as a drug target in human disease. Trends Pharmacol Sci 2009; 30: 95-103.

15 Ivanov S, Lindén A. Th-17 cells in the lungs? Expert Rev Respir Med 2007; 1: 279-293.

16 O'Grady NP, Preas HL, Pugin J, et al. Local inflammatory responses following bronchial endotoxin instillation in humans. Am J Respir Crit Care Med 2001; 163: 1591-1598.

17 Lind K, Kubista M. Development and evaluation of three real-time immuno-PCR assemblages for quantification of PSA. J Immunol Methods 2005; 304: 107-116.

18 Ivanov S, Bozinvoski S, Bossios S, et al. Functional relevance of the IL-23-IL-17 axis in lungs in vivo. Am J Respir Cell Mol Biol 2007; 36: 442-451.

19 Prause O, Bossios A, Silverpil E, et al. IL-17-producing T lymphocytes in lung tissue and in the bronchoalveolar space after exposure to endotoxin from Escherichia coli in vivo - effects of antiinflammatory pharmacotherapy. Pulm Pharmacol Ther 2009; 22: 199-207.

20 Laan M, Palmberg M, Larsson K, et al. Free, soluble interleukin-17 protein during severe inflammation in human airways. Eur Respir J 2002; 19: 534-537.

21 Ivanov S, Palmberg M, Venge $P$, et al. Interleukin-17A mRNA and protein expression within cells from the human bronchoalveolar space after exposure to organic dust. Respir Res 2005; 6: 44.

22 Barczyk A, Pierzchala W, Sozanska E. Interleukin-17 in sputum correlates with airway hyperresponsiveness to methacholine. Respir Med 2003; 97: 726-733.

23 Dheda K, Chang JS, Lala S, et al. Gene expression of IL17 and IL23 in the lungs of patients with active tuberculosis. Thorax 2008; 63: 566-568.

24 Molet S, Hamid Q, Davoine F, et al. IL-17 is increased in asthmatic airways and induces human bronchial fibroblasts to produce cytokines. J Allergy Clin Immunol 2001; 108: 430-438.

25 Vanaudenaerde BM, Dupont LJ, Wuyts WA, et al. The role of interleukin-17 during acute rejection after lung transplantation. Eur Respir J 2006; 27: 779-787.
26 Di Stefano A, Caramori G, Gnemmi I, et al. T helper type 17-related cytokine expression is increased in the bronchial mucosa of stable chronic obstructive pulmonary disease patients. Clin Exp Immunol 2009; 157: 316-324.

27 Acosta-Rodriguez EV, Rivino L, Geginat J, et al. Surface phenotype and antigenic specificity of human interleukin 17-producing $\mathrm{T}$ helper memory cells. Nat Immunol 2007; 8: 639-646.

28 Scriba TJ, Kalsdorf B, Abrahams DA, et al. Distinct, specific IL-17and IL-22-producing $\mathrm{CD}^{+} \mathrm{T}$ cell subsets contribute to the human anti-mycobacterial immune response. J Immunol 2008; 180: 1962-1970.

29 Nograles KE, Zaba LC, Shemer A, et al. IL-22-producing “T22" T cells account for upregulated IL-22 in atopic dermatitis despite reduced IL-17-producing TH17 T cells. J Allergy Clin Immunol 2009; 123: 1244-1252.e2.

30 Whittington HA, Armstrong L, Uppington KM, et al. Interleukin22: a potential immunomodulatory molecule in the lung. Am J Respir Cell Mol Biol 2004; 31: 220-226.

31 Annunziato F, Cosmi L, Santarlasci V, et al. Phenotypic and functional features of human Th17 cells. J Exp Med 2007; 204: 1849-1861.

32 Shen H, Goodall JC, Hill Gaston JS. Frequency and phenotype of peripheral blood Th17 cells in ankylosing spondylitis and rheumatoid arthritis. Arthritis Rheum 2009; 60: 1647-1656.

33 Stritesky GL, Yeh N, Kaplan MH. IL-23 promotes maintenance but not commitment to the Th17 lineage. J Immunol 2008; 181: 5948-5955.

34 Manel N, Unutmaz D, Littman DR. The differentiation of human $\mathrm{T}_{\mathrm{H}^{-}}-17$ cells requires transforming growth factor- $\beta$ and induction of the nuclear receptor ROR $\gamma$ t. Nat Immunol 2008; 9: 641-649.

35 McGeachy MJ, Chen Y, Tato CM, et al. The interleukin 23 receptor is essential for the terminal differentiation of interleukin 17producing effector T helper cells in vivo. Nat Immunol 2009; 10: 314-324.

36 Bauquet AT, Jin $\mathrm{H}$, Paterson AM, et al. The costimulatory molecule ICOS regulates the expression of c-Maf and IL-21 in the development of follicular $\mathrm{T}$ helper cells and $\mathrm{T}_{\mathrm{H}}-17$ cells. Nat Immunol 2009; 10: 167-175.

37 Huber M, Brüstle A, Reinhard K, et al. IRF4 is essential for IL-21mediated induction, amplification, and stabilization of the Th17 phenotype. Proc Natl Acad Sci USA 2008; 105: 20846-20851.

38 Budagian V, Bulanova E, Paus R, et al. IL-15/IL-15 receptor biology: a guided tour through an expanding universe. Cytokine Growth Factor Rev 2006; 17: 259-280.

39 Ma A, Koka R, Burkett P. Diverse functions of IL-2, IL-15, and IL-7 in lymphoid homeostasis. Annu Rev Immunol 2006; 24: 657-679.

40 Ziolkowska M, Koc A, Luszczykiewicz G, et al. High levels of IL-17 in rheumatoid arthritis patients: IL-15 triggers in vitro IL-17 production via cyclosporin A-sensitive mechanism. J Immunol 2000; 164: 2832-2838.

41 Koenen HJ, Smeets RL, Vink PM, et al. Human CD25 ${ }^{\text {high }} F_{\text {Foxp3 }}{ }^{\text {pos }}$ regulatory $\mathrm{T}$ cells differentiate into IL-17-producing cells. Blood 2008; 112: 2340-2352.

42 Aujla SJ, Chan YR, Zheng M, et al. IL-22 mediates mucosal host defense against Gram-negative bacterial pneumonia. Nat Med 2008; 14: 275-281. 